\title{
Influence of Distribution on Sales Performance of Vehicle Entertainment Distributors in Nairobi-Kenya
}

\author{
Rachael N. Wambua ${ }^{1 *} \quad$ Dr. Mary Mwanzia ${ }^{2}$ \\ 1.School of Business, Mount Kenya university, PO Box 342-01000, Thika, Kenya \\ 2.Senior Lecturer, Mount Kenya University, PO Box 342-01000, Thika, Kenya
}

\begin{abstract}
Successful distribution channel selection, implementation and management cannot only help to meet the shopping needs and habits of the target customers efficiently under the cost constraints but must also mitigate the disadvantages caused by distribution channel conflicts. The objective of the study was to establish the effect of distribution strategies on sales performance of vehicle entertainment distributors in Nairobi, Kenya. Descriptive research design was adopted for the study. The study used primary data collected through structured questionnaires. Descriptive statistics such as means and standard deviation and regression analysis were for data analysis. Simple linear regression analysis obtained a statistically significant relationship between distribution and sales performance of vehicle entertainment distributors. The study therefore concluded that market distribution strategies resulted to increased sales, profits and market share of vehicle distributors within the region. It also enhances the distributors' ability to effectively respond to market changes.
\end{abstract}

Keywords: Distribution, Successful implementation, Sales Performance

DOI: $10.7176 / \mathrm{EJBM} / 12-26-04$

Publication date:September $30^{\text {th }} 2020$

\section{Introduction}

According to (Grashey et al., 2000), marketing entails more than just selling what a business enterprise manufactures or merely advertising what it has to offer. The authors stress that it is however regards making decisions about "what to do and for whom". In practice, marketing should lead the strategy of the firm towards making what can be sold, not selling what can be made. The competitiveness in the technological-based economies and globalized environment has led to an increased significance of marketing to boost sales; profitability margins and enable organizations survive in future (Mintz \& Currim, 2013). Marketing is perceived as a process focusing on creation and fulfillment of the wants and needs of customers. As a process, marketing makes sure that all programs are consistently presented in a manner that capture the needs and wants of customers. Thus, marketing ensures that a target market of the company is clearly defined and appropriate marketing mix are established. Marketing ensures that the needs and wants of the identified market segments are clearly identified and adequate measures are in place to ensure satisfaction (Best, 2012).

The increased level of competition coupled with globalization has affected the performance of organizations in the current world. It requires firms to come up with effective marketing strategies in response to these factors of competition so as to remain competitive and enhance their performance in the industry. Customers today are more knowledgeable with ever changing needs and preferences regarding the brands of music devices that they would want to purchase and even the type of music that they would love to listen to. The management team of organizations today is presented with a challenge of deciding the best marketing strategy that would result into significant performance of their organizations (Jacobson, 2012)

Performance of a firm is usually measured in a variety of parameters which include; sales, market share, or profitability. The firm performance measures highlighted here have a high correlation, thus picking out one will automatically represent the others. The current study will measure firm performance as indicated by volume of sales. Marketing mix activities do not affect sales performance each in isolation but they require to be well synchronized in order for them to interact and in the process boosting sales performance (Gatington, 1993). This will aid managers in taking advantage of the complementarities thus avoiding incompatibility between marketing mix tools given constraints by budget and the variables themselves

\section{Statement of the Problem}

The vehicle entertainment industry has grown over the years with a lot of players entering the field due to increased demand and expansion of the market. Lots of people are spending time on the road hence the need for entertainment, which has led to many companies joining in the sector and increasing competition. As one of the fundamental asset of a company's success, selecting a proper distribution channel has been a focal point in both supply chain and marketing channel structure. Decisions on the distribution strategy are usually based on the finding that it's the most profitable way to reach the market (Ford \& Mottner, 2003). Successful distribution channel strategy selection, implementation and management cannot help to meet the habits and shopping needs of target customers efficiently under the constraints of the seller but also reduce the disadvantages caused by distribution channel 
conflicts such as double marginalization. A company's distribution strategy of its products and services is an important strategic asset. Statistics on the automotive entertainment devices as from 1950 to 2030 show that in 2010 , the electronics and entertainment content accounted for $20 \%$ of the total production of the automobile (Mintz and Currim, 2013). This statistics portray the significance of music entertainment systems in automotive and hence the need to undertake a detailed study on the distribution networks of vehicle entertainment distributors in Nairobi, Kenya.

\section{Literature Review}

To adequately review the related literature in this survey, this section is segmented into the theoretical framework and the empirical review.

\section{Theoretical Review}

Marketing Mix Theory -Although coined by Borden, organizations today leverage on the marketing mix theory to decide on critical marketing issues (Kotker and Keller, 2006). The whole idea behind the marketing mix theory is to effectively organize marketing plan efforts (McCarthy, 2004). The marketing mix theory is founded on the 4Ps. Product as the first $\mathrm{P}$ considers features and design of the good relative to competitors. Price, as the second $\mathrm{P}$ can be modified in response to demand in determination of profit margin. Promotion as the third P requires a decision on the media to use in creating awareness to customers regarding the products. The fourth $\mathrm{P}$, placement determines a suitable place for customers to access the products of the company.

Young people may have strong preference of online tools and platforms while personal selling may be appealing to others. Later on, Robert (2012) came up with 4Cs classification that is just a modification of the 4Ps. These 4Cs stand for convenience, communication, cost and consumers. This marketing mix theory had relevant implication in modern marketing efforts of any company. First, sales forces will only close a deal when customers need the products being promoted/supplied/advertised by the sales force. Thus, the needs and wants of consumers inform customers to purchase given products.

Price is only a mere portion to the overall cost of satisfaction of the needs and wants of customers. The overall costs entail costs of time spend in acquisition of a product proper dialogue with customers in view of their preferences and needs. Communication can be achieved through advertisement, public relations and personal selling.

The theory was used in this study because it links the marketing mix variables with sales performance. An organization can leverage on these variables to offer quality products that meet the needs of customers and therefore greater performance.

\section{Empirical Review}

Place is a distribution strategy used by a firm to get services and products to different networks and channels so as to reach the end customer. The intermediaries can either be agents, wholesalers, distributors or retailers. These elements seek to ensure that customers receive quality services from the firm which fully meet their level of customer satisfaction (Palmer, 2011). The services and products must also be delivered to the customer in the most convenient manner and thus aspects such as physical access must be highly considered.

Distribution channels are vital in describing the level of competitiveness of the firm since they influence the final price of the product and the time when the product reaches the customer. Through distribution strategy, a firm gets to understand the sales channels through enhanced knowledge, better segmentation on the distribution within the sales channels, the roles played by the intermediaries on the sales process, getting to articulate the centers of influence on the sales channel as well as the firm's position with regards to the sales channel (Whetton, 2011).

A study was conducted by (Langat, 2016) to determine how marketing mix variables affected performance of projects in an enterprise. The study used a case of Safaricom Ltd. The study established that distribution strategy had significant influence of performance of the firm. The study established that effective pricing strategies positively affected performance. The findings of the study showed that efficient promotion strategies resulted into greater customer satisfactions that ultimately affected performance of an organization.

[13] Investigated how distribution strategies of the company affected performance. The study established that the channels of distributing products of the company had positive correlation with performance of an organization. The study established that effective distribution strategies reduced delivery time resulting into greater customer satisfaction. The findings of the study indicated that efficient distribution systems helped customers to access products of the company in real time.

Mccarthy (2004), carried out a study to access how innovations in distribution channels affected performance. The study covered small and medium enterprises. The study established that an increased innovation and investment in distribution channels significantly affected performance of SMEs. Among the significant challenges encountered in serving of the market is safeguarding a constant supply of products to the market or among 
consumers ( Jacobson, 2012). One company that has been of success in its distribution strategies is Safaricom Ltd. It currently has 2,000 branches dealing in its products with over 200,000 retailers dealing in its products. These distribution strategies explained a growth in sales growth by over 140 percent with a sales revenue of over 3.5 billion (McCarthy, 2004).

\section{Methodology}

The study adopted the descriptive research design using quantitative approach. The data was collected using structured questionnaires. Data collected was sorted, edited and fed into statistical package for social sciences for analysis. Descriptive statistics was performed to generate means and standard deviation while inferential statistics was undertaken using the simple linear regression analysis to establish whether there was any relationship between distribution strategies and sales performance of vehicle entertainment distributors.

\section{7 .Findings and Discussions}

The study also measured the extent to which distribution influences the sales performance of vehicle entertainment distributors in Nairobi, Kenya. The respondents were presented with different statements on place and the findings were as presented below

\begin{tabular}{|l|c|c|c|}
\hline Items & N & Mean & $\begin{array}{l}\text { Std. } \\
\text { Deviation }\end{array}$ \\
\hline The distribution channel impacts the export profit level & 45 & 4.0444 & .79646 \\
\hline The distribution channel dependent on the competitive & 45 & 3.8667 & .75679 \\
\hline Distribution strategy positively impacts firm performance in profit level. & 45 & 3.7778 & .82266 \\
\hline Distribution adaptation helps an organization to improve its sale performance. & 45 & 3.7111 & .54864 \\
\hline $\begin{array}{l}\text { Distribution strategy positively impacts firm performance in terms of export } \\
\text { proportion of sale }\end{array}$ & 45 & 3.4667 & .91949 \\
\hline The distribution channel dependent on the structure of distribution & 45 & 3.4667 & 1.01354 \\
\hline The delivery time of products influence the export performance of firms & 45 & 3.4222 & .65674 \\
\hline The distribution channel dependent on the economic situation & 45 & 3.3556 & .93312 \\
\hline Average & $\mathbf{4 5}$ & $\mathbf{3 . 6 3 8 9}$ & $\mathbf{0 . 8 0 5 9 3}$ \\
\hline
\end{tabular}

Upon the assessment of the different attributes of distribution, the means and standard deviations attained were as follows; the distribution channel impacts the export profit level (M-4.0444, SD-79646), the distribution channel dependent on the competitive (M-3.8667, SD-.75679), distribution strategy positively impacts firm performance in profit level (M -3.7778,SD- 0 .823), distribution adaptation helps an organization to improve its sale performance (M-3.7111, SD-.54864), distribution strategy positively impacts firm performance in terms of export proportion of sale (M-3.4667, SD-0.91949), the distribution channel dependent on the structure of distribution (M-3.4667, SD-1.01354) the delivery time of products influence the export performance of firms (M3.4222, SD- .65674) and the distribution channel dependent on the economic situation (M- 3.3556, SD- .93312). The overall mean attained was 3.639 implying that place is a crucial determinant of the vehicle entertainment distributor's sales performance. These results affirm with Amara (2013) that channels of distributing products of the company had positive correlation with performance of an organization.

\section{Relationship between distribution strategies and sales performance}

A regression analysis was performed to establish the association between marketing strategies and sales performance of motor vehicle entertainment distributors in Nairobi. The output was as presented in the tables below

Model Summary

\begin{tabular}{|l|l|l|l|l|}
\hline Model & $\mathrm{R}$ & $\mathrm{R}^{2}$ & Adjusted $\mathrm{R}^{2}$ & Std. Error of the Estimate \\
\hline 1 & $.664^{\mathrm{a}}$ & .441 & .422 & .54363 \\
\hline
\end{tabular}

a. Predictors; Distribution

The $\mathrm{R}^{2}$ value in the model was 0.441 meaning that $44.1 \%$ of the variation in sales performance can be predicted by distribution while $55.9 \%$ was attributed to other factors not considered in the study

Analysis of Variance

ANOVA
\begin{tabular}{|ll|l|l|l|l|l|}
\hline Model & & Sum of Squares & df & Mean Square & F & Sig. \\
\hline \multirow{4}{*}{1} & Regression & 20.547 & 1 & 6.849 & 23.175 & $.000^{\mathrm{b}}$ \\
& Residual & 26.007 & 43 & .296 & & \\
& Total & 46.554 & 44 & & & \\
\hline
\end{tabular}

The results from analysis of variance produced a P value of 0.000 . The $p$ value of 0.000 implies that the model 
was significant and that there exists a statistically significant relationship between sales performance and sales performance of vehicle entertainment distributors.

Coefficients

\begin{tabular}{|ll|l|l|l|l|l|}
\hline \multirow{2}{*}{ Model } & \multicolumn{2}{|l|}{ Unstandardized Coefficients } & Standardized Coefficients & $\mathrm{t}$ & \multirow{2}{*}{ Sig. } \\
\cline { 2 - 6 } & $\mathrm{B}$ & Std. Error & Beta & & \\
\hline \multirow{2}{*}{1} & (Constant) & .109 & .223 & & 0.489 & .000 \\
\cline { 2 - 5 } & Distribution & .444 & .084 & .496 & 5.278 & .000 \\
\hline
\end{tabular}

a. Dependent Variable: Sales Performance

Therefore, the simple linear regression model becomes;

$\mathrm{Y}=0.109+0.444 \mathrm{X}_{1}$

The hypothesis tested on differentiation stated that that there is no significant relationship between distribution strategies adopted by motor vehicle entertainment distributors and sales performance. The study findings indicated that there was a significant relationship between distribution strategies and performance of motor vehicle entertainment distributors. Distribution with a beta of 0.444 was at a statistically significant level and was a good predictor of performance implying that an increase in differentiation by one unit would result to 0.444 positive improvement in sales performance of vehicle entertainment distributors.

\section{Conclusion and Recommendations}

The role of distribution strategy on sales performance of motor vehicle entertainment distributors is real and practical as established in the study. The study established that the growth noticed during the study timeframe was majorly attributed to the aggressive marketing strategies adopted by the distributors. The study concludes that a well-coordinated distribution strategy is the strategic driver of the organizational positioning in a dynamic environment that helps companies to extend the consumption of products in existing or venture into new markets. The research established that the sales performance of an organization can greatly be determined by the distribution strategy employed by the establishment and thus recommends that the implementation process of these strategies should be given top priority particularly in terms of resource allocation and ensuring successful implementation. The vehicle entertainment distributors should also adopt the most effective and efficient distribution channels to cut on their costs so as to offer their products at the most affordable costs to attract more customers.

Further, the adoption of distribution strategies should be supported by understanding the vehicle entertainment industry, trends in the environment, the needs of the target consumer segments and the positional advantages being sought. This will improve the market share and sales performance of the distributors.

\section{References}

A. Palmer (2011). Principles of Services Marketing (3rd ed.). UK: McGraw-Hill Publishing Company. Grasby, M Crossan, Frost, M Haywood-Farmer, J., M. Pearce, \& L. Purdy, (2000). Business decisions: Text and cases. Ontario: Thomson Learning

H. Gatington, (1993). Marketing Mix Model (eds) Handbook in OR and MS Vo. 5 Elsievier science Publisher.

J.B. Ford and S. Mottner. (2003), Retailing in the non-profit sector: an exploratory analysis of church-connected retailing ventures, International Journal of Non-profit and Voluntary Sector Marketing, Vol. 8 pp.337-48

J.C McCarthy (2004). The context of information use in a hospi-tal as simultaneous similarity-difference relations. Cognition, Technology and Work1, 1: 25-36.

M. Jacobson (2012). Mastering Multi-Camera Techniques: From Pre-Production to Editing to Deliverable Masters. CRC Press.

N. Langat. (2016). Influence of product, price, promotion and place on enterprise project performance: a case of Safaricom enterprise project, Uasin Gishu County, Kenya. Unpublished journal of the University of Nairobi 2(1) 23-44

O. Mintz and I.S Currim, (2013). What drives managerial use of marketing and financial metrics and does metric use affect performance of marketing-mix activities?. Journal of Marketing, 77(2), 17-40.

P. Kotler and G. Keller (2006). Principles of Marketing. Upper Saddle River, NJ: Pearson Prentice Hall.

R. Best, (2012). Market-based management. Pearson Higher Ed

R.M. Robert (2000), "The comparative advantage theory of competition Using 4Cs Model ", Journal of Marketing: 59, pp. 1-15

S.Amara, (2012). The Effect of Marketing Distribution Channel Strategies on a Firm's Performance among Commercial Banks in Kenya. School of Business, University of Nairobi.

Whetton (2011). Organizational Effectiveness: A Comparison of Multiple Models (pp. 261-77). New York,NY: Academic Press. 